\title{
A toolkit for creating healthy food and drink environments in community food retail outlets
}

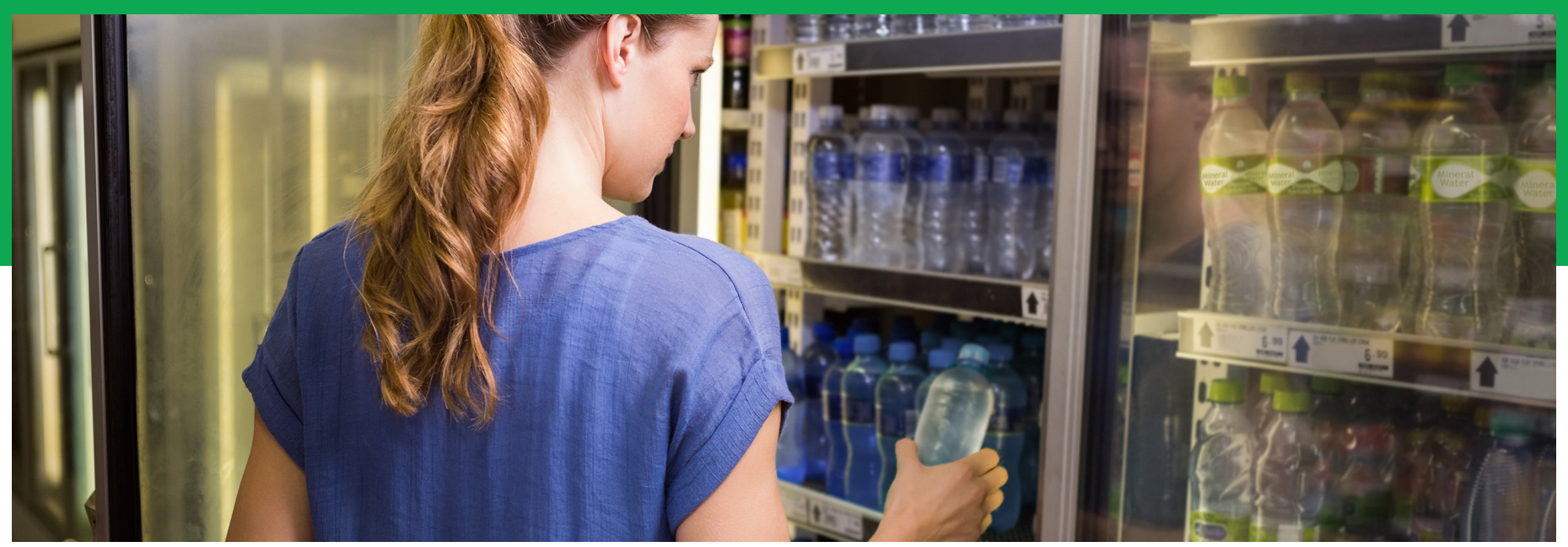

\section{Introduction}

The type of food and drinks that are available for purchase significantly influence people's food and drink choices.

Research shows that the environments in which we live, work, learn, and play are key drivers of the types of food and drink we consume ${ }^{1}$.

We are surrounded by unhealthy food and drinks and this is a key driver of poor diet, which is a risk factor for obesity, cardiovascular diseases, type 2 diabetes, and several cancers ${ }^{2}$.

But there is good news - local governments can make a positive difference, by implementing policies and practices to improve local food and drink environments ${ }^{3}$.

By providing healthy food retail environments in council-owned facilities, local governments can support community health and wellbeing.

This can be done by increasing the availability of healthy food and drink options for sale and reducing the availability and promotion of unhealthy foods and sugary drinks.

One way we can do this is by ensuring that popular children's venues like sports and recreation facilities are free from unhealthy food and sugary drinks and instead stocked with delicious, healthy options kids will love.

This toolkit uses the latest evidence to guide local government action on providing healthy food retail environments in councilowned facilities.

It is based on the experience of the VicHealth Water in Sport project, in which 8 Victorian local government areas successfully implemented practices and policies to encourage consumption of water and reduce sugary drinks in their sport and recreation or club facilities from 2018-2020.
"We are calling on local governments to take a leading role in creating healthy food environments in their communities."

\section{What does this toolkit offer you?}

Throughout the Water in Sport project, we have learnt a lot about how to successfully create healthy food retail environments. This toolkit focuses on the changes made to drinks during the project. However many recommendations may also be applied to making changes to food. It provides:

- advice on determining which community food retail outlets to work with and how to engage them

- suggestions for which healthy changes to make and where to start

- step-by-step advice on how to implement, monitor and assess changes in community food retail settings to encourage healthier eating and drinking

- a range of data collection tools, and collated marketing and training resources created by the Water in Sport project officers and the Healthy Eating Advisory Service

- recommendations for policy development to support healthy food retail environments.

\section{Who is this toolkit for?}

If you're interested in supporting the health of your community, this toolkit is for you!

This toolkit is designed for health promotion officers (or similar) employed by a local government wanting to create a healthy food environment within their community food retail outlets, including sport and recreation facilities, arts centres, community halls, libraries, and club facilities.

1 Schwartz MB, Just DR, Chriqui JF, Ammerman AS. Appetite self-regulation: Environmental and policy influences on eating behaviors. Obesity. 2017;25:S26-S38

2 Global Burden of Disease Risk Factors Collaborators. Global, regional, and national comparative risk assessment of 79 behavioural, environmental and occupational, and metabolic risks or clusters of risks, 1990-2015: a systematic analysis for the Global Burden of Disease Study 2015. Lancet. 2016;388(10053):1659-1724

3 Allender S, Gleeson E, Crammond B, Sacks G, Lawrence M, Peeters A, et. al. 2012. Policy change to create supportive environments for physical activity and healthy eating: which options are the most realistic for local government? Health Promotion International, 27(2), $261-274$. 


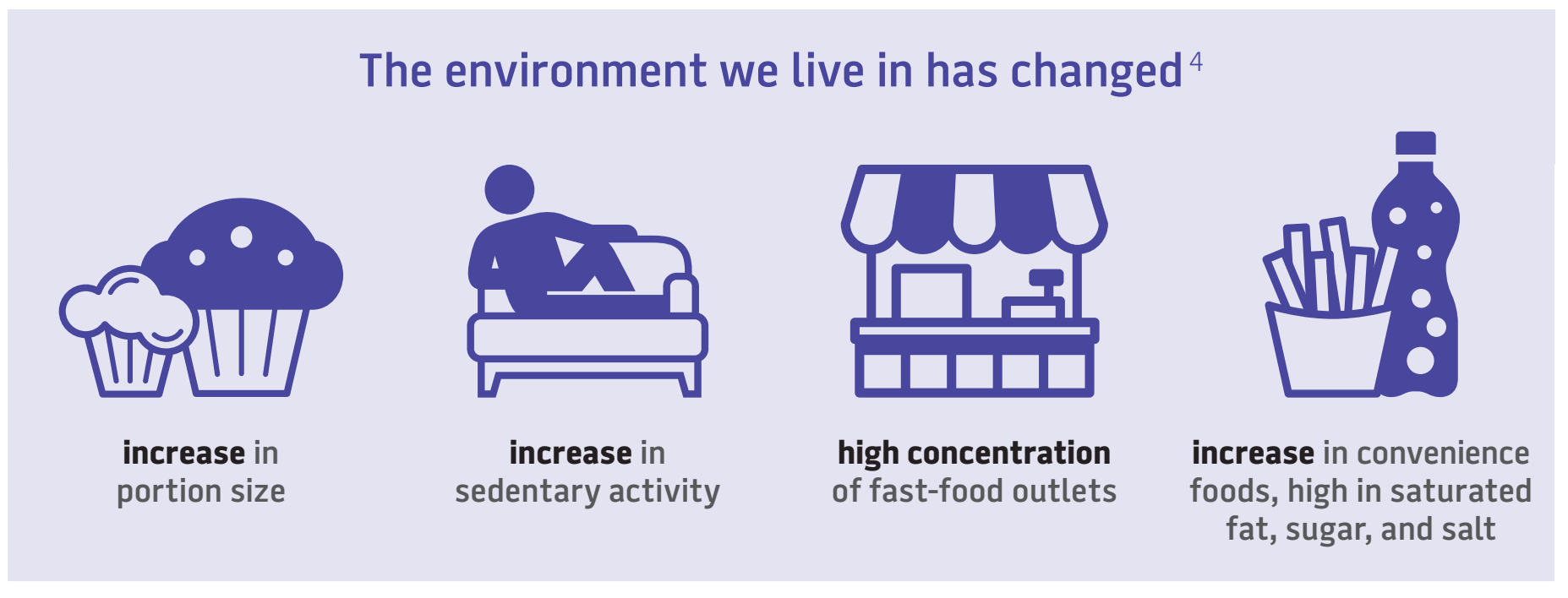

As a result, our diets have shifted to being higher in processed foods and sugary drinks and low in fruits and vegetables ${ }^{5,6}$

\section{$43 \%$}

of adults meet recommendations for fruit intake

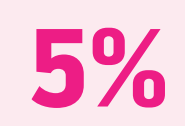

of adults meet recommendations for vegetable intake

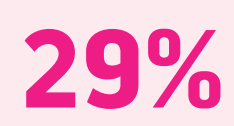

of adults consume sugary drinks at least once per week

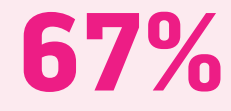

of adolescents meet of adolescents meet recommendations for fruit intake

\section{$13 \%$}

recommendations

for vegetable intake

\section{This impacts our health}

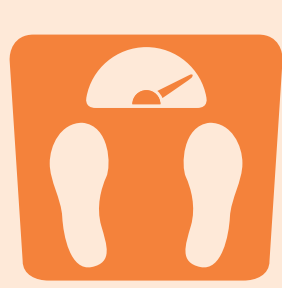

$68 \%$ of adults and $23 \%$ of children are living with overweight or obesity. ${ }^{7,8}$
There is community support for healthy food retail environments

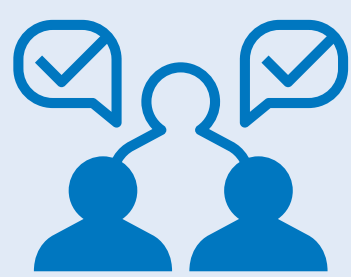

\section{$75 \%$ of customers} surveyed during the Water in Sport project believed that sport and recreation facilities should promote healthy eating.

\footnotetext{
4 Sallis JF, Glanz K. The role of built environments in physical activity, eating, and obesity in childhood. The Future of Children. 2006:89-108 5 Victorian State Government. Victorian Population Health Survey 2017. 2018. [Cited Nov 2020]. Available from: www.health.vic.gov.au

6 Victorian State Government. Victorian student health and wellbeing survey 2018. 2020. [Cited Nov 2020]. Available from: www.education.vic.gov.au 7 Victorian State Government. Overweight and obesity. [Cited Nov 2020]. Available from: www.health.vic.gov.au

8 Australian Bureau of Statistics. 4364.0.55.001 National Health Survey: First Results 2017-2018. 2019.[Cited Nov 2020]. Available from: www.abs.gov.au
} 


\section{About the Water in Sport project}

The Water in Sport project ran from 2018-2020, with funding provided by VicHealth to 8 Victorian local government areas to each employ a project officer. Project officers helped their local government-owned and/or managed sport and recreation or club facilities to introduce a 'nudge' to encourage customers to purchase healthier drinks.

Subtle environmental changes or 'nudges' were chosen for the Water in Sport project, such as cues to influence our food and drink purchases. Nudges consisted of either limiting sugary drink availability to less than $20 \%$ of fridge display, or completely removing sugary drinks from view.

Drinks available at each outlet were classified according to the Victorian Government's Healthy Choices guidelines as 'GREEN' ('best choice'), 'AMBER' ('choose carefully') or 'RED' ('limit').
Nutrition Australia Vic Division provided intensive support to the project officers via the Healthy Eating Advisory Service, and the Global Obesity Centre at Deakin University evaluated the impact of the changes made.

The 8 funded local governments were:

- East Gippsland

- Frankston

- Greater Geelong

- Greater Bendigo

- Greater Shepparton

- Melton

- Northern Grampians

- Yarra Ranges

\section{The Healthy Eating Advisory Service, Nutrition Australia, Vic Division}

The Healthy Eating Advisory Service (HEAS) supports local governments, sport and recreation facilities and other community settings to provide and promote healthier foods and drinks.

HEAS can help you to:

- take the steps to make healthy food and drink changes in your organisation

- understand how to apply government food and drink policies and guidelines
- train your cooks, chefs, food service and other key staff

- discover healthier recipes, food ideas and other helpful resources

- provide healthier menus and products.

HEAS is delivered by experienced nutritionists and dietitians at Nutrition Australia Vic Division, with support from the Victorian Government. You can visit the HEAS website for more details and to get in touch.

\section{What were the results of the Water in Sport project?}

At the conclusion of the Water in Sport project, 39 sport and recreation clubs and facilities implemented at least 1 nudge in each local government area. Overall, the proportion of 'RED' drinks available decreased from $39 \%$ to $11 \%$ of all drinks, and the proportion of 'GREEN' drinks available increased from $43 \%$ to $63 \%$.

Different sales trends were observed in seasonal and non-seasonal facilities. Following nudge implementation, in 8 seasonal facilities, the 'RED' drinks purchased decreased from $48 \%$ to $25 \%$ of all drinks. The percentage of 'GREEN' drinks purchased increased from $41 \%$ to $51 \%$. There was no change in drinks revenue.

The volume of 'RED' drinks sold (as a percentage of all drinks) decreased in 6 of 10 non-seasonal facilities and increased in 2 facilities. The volume of 'GREEN' drinks sold increased in 4 of 10 non-seasonal facilities and decreased in 1 facility. In 9 out of 10 facilities, there was no change in drinks revenue. To see results for the Water in Sport project for each council, go to the VicHealth website.

\section{General principles for success}

- Form a working group which brings together council staff from diverse areas including; health promotion, procurement, environmental sustainability, and the target intervention setting (e.g. sports and recreation).

- Identify who the 'champion' will be at the community food retail outlet and build relationships early on.

- Promote open communication with the outlet and work with them to establish goals that align with their values.
- Start by trialling a small 'easy win' as these are unlikely to have any significant negative impact (e.g. rearrange the fridge to put 'GREEN' drinks at eye-level).

- Establish a local community-of-practice to share and build new knowledge, resources and support amongst community food retail outlets within your local government and surrounding areas.

- Consider a tiered policy approach to allow for different implementation expectations depending on outlet capacity and level of council influence. 


\subsection{Decide which retail food outlets to work with and how}

Before any healthy changes are made, it is important to determine how ready local governments and outlets are to change. This includes understanding their commitment, capacity and current challenges and opportunities to making changes. This can help determine how many outlets are in scope for the project, which outlets will be more likely to make changes and what resources and timelines will be required to support the outlet. Once you know this information, you can adjust your plans accordingly. Ways of assessing readiness to change can include having a targeted conversation with a key representative, such as the outlet manager and a local government representative. Key questions to ask the representative are in Resource 1: Readiness to change assessment.

Who should be involved in the readiness for change conversation at local government?

Local government structure varies from area to area. It is therefore important to understand which people will be aware of local government priorities and resources for healthy food environments. They may be a:

- health and wellbeing manager

- community development officer

- sport and recreation officer

- environmental health officer

- health promotion officer

- social and community planner.

\subsection{Form a working group}

A working group should be formed early on to support and guide the change. A working group should include key stakeholders and local government leaders from different council areas including:

- health promotion

- procurement

- environmental sustainability

- the target intervention setting (e.g. sports and recreation).

The working group will be responsible for developing a strategic, phased approach to implementing healthy retail policies. The implementation plan should set out strategies to:

- integrate into the municipal plan

- develop internal council policies and procedures

- engage councillors

- develop relationships with retailers

- prioritise long-term maintenance planning.
Key questions and tasks for working groups:

How will we monitor healthy food retail compliance?

»Embed healthy food retail checks with other regular compliance checks.

How can we ensure healthy food retail is a long-term priority?

»Develop a policy.

How can we support healthy food retail when planning new facilities?

» do not install a deep fryer

» ensure sufficient food preparation space

» consider digital menus to allow promotion of healthy options

» incorporate healthy retail requirements into the municipal public health and wellbeing plan.

\section{Useful skills to support change:}

When you are working with outlets to help improve their food and drink offerings, the following skills and experience can be useful for you or your colleagues to have:

- stakeholder engagement

- project management

- retail experience in hospitality

- health promotion or public health expertise.

\subsection{Meet with community retail outlets}

Success is driven by individuals working together to support, champion, and implement change. Identify who the decision-makers and implementors (people putting the healthy change into effect) are at the outlet and build relationships early on. Early discussions can lead to collaborative partnerships that support working with the outlet to provide relevant and useful strategies to assist and guide healthy food and drink changes. These conversations will allow you to discuss any challenges and support needed.

\section{Priorities and values of food retail outlets:}

When meeting with the outlet staff you may find it useful to discuss the outlet's priorities and values. You could align your pitch for healthy changes with the outlet's values.

Key priorities or values that may be important to community retail outlets:

- supporting customers to make healthier choices

- supporting local businesses

- maintaining profit

- fairness for all customers related to pricing of food and drinks

- customer satisfaction with the healthy changes

- environmental sustainability (e.g. limiting food waste or use of plastic bottles). 


\subsection{Understanding the outlet's capabilities}

Identifying challenges and opportunities to implement a change is important to assess early. You can use the following questions to assess an outlet's current capability to adopt healthy changes. This will help to determine which changes will be appropriate for the outlet.

\begin{tabular}{l|ll} 
State of play & Key questions & Implications \\
Staff & $\begin{array}{l}\text { - Are the staff paid or voluntary? } \\
\text { - How many staff members are there? }\end{array}$ & $\begin{array}{l}\text { Understanding staff capacity and } \\
\text { availability will help you to determine how } \\
\text { to best communicate changes and plan } \\
\text { education of staff, where possible. }\end{array}$
\end{tabular}

Opening hours $\quad$ What are the outlet's operating hours?

Opening hours will impact your ability to meet with the outlet staff and provide support.

\begin{tabular}{|c|c|c|}
\hline Fridge display & $\begin{array}{l}\text { - Is the fridge visible to customers? } \\
\text { - Are the drinks inside the fridge visible to customers? }\end{array}$ & $\begin{array}{l}\text { The fridge display will impact the types o } \\
\text { changes that can be made. }\end{array}$ \\
\hline Food display & $\begin{array}{l}\text { - Is the food visible to customers? } \\
\text { - Is there a menu listing what's available? } \\
\text { - What is visible at the register/point of sale? }\end{array}$ & $\begin{array}{l}\text { The food display will impact the types of } \\
\text { changes that can be made. }\end{array}$ \\
\hline $\begin{array}{l}\text { Advertising and } \\
\text { promotions }\end{array}$ & $\begin{array}{l}\text { - What type of food and drink are advertised or promoted? } \\
\text { - What brands are promoted on fridges and display cases? } \\
\text { - What specials or deals are being promoted? }\end{array}$ & $\begin{array}{l}\text { Advertising may be targeted to promote } \\
\text { healthier food and/or drink options. } \\
\text { Branding and promotion of unhealthy } \\
\text { foods and drinks should be removed } \\
\text { from sight. }\end{array}$ \\
\hline
\end{tabular}

supply

\section{Food and drink}

- How does the outlet prepare or purchase their food and drinks?

- What equipment or appliances are in the outlet to help prepare foods and drinks?

- Does the outlet have supplier contracts?
Food and drinks preparation capabilities and purchasing can influence the type of food and drinks available. Contracts with suppliers may mean you are restricted with what options can be offered.

\section{Lease agreements}

\section{Previous healthy changes}

- What is the length of the current outlet lease agreement?

- Does the lease agreement include any requirements to provide healthy food and/or drink?
Lease agreements can be used to encourage outlets to provide healthy options and can be added as a requirement of their lease agreement. 


\subsection{Understanding the current food and drink environment}

Assessing the environment before any healthy changes are made can help identify priority areas and can be useful to track progress. Using the 4 Ps of marketing - product, price, place and promotion - can help ensure you understand every aspect of how food and drinks are marketed to customers. Here are some ways that you can assess the situation:

\begin{tabular}{l|l}
$\begin{array}{l}\text { Marketing Strategy } \\
\begin{array}{l}\text { Product (the food and drink } \\
\text { available) }\end{array}\end{array}$ & $\begin{array}{l}\text { Assess current environment } \\
\text { Take photos of the drink fridge, vending machine or food display (Resource 2: Step-by-step photo audit). } \\
\text { Input relevant data into FoodChecker, an online food and drink assessment tool. }\end{array}$ \\
\hline $\begin{array}{ll}\text { Price (what the customer pays) } \\
\text { Plakn (the location of the } \\
\text { food and drink) }\end{array}$ & $\begin{array}{l}\text { Take photos of the food outlet showing where the foods and drinks are placed and complete the food } \\
\text { and drink environment audit (Resource 3: Food and drink environment audit). }\end{array}$ \\
\hline $\begin{array}{l}\text { Promotion (the advertising) } \\
\text { Take photos of any promotional material advertising a product, this includes branding on drink fridges, } \\
\text { display cases and posters (Resource 2: Step-by-step photo audit). }\end{array}$
\end{tabular}

Healthy Choices guidelines

The Victorian Government developed the Healthy Choices guidelines to help ensure healthy food and drinks are available and promoted in a variety of settings. The Healthy Choices guidelines use a traffic light system to classify foods and drinks as 'GREEN' (best choice), 'AMBER' (choose carefully) or 'RED' (limit). FoodChecker is a free online tool that supports individuals and businesses to classify their products, recipes and menus and receive a report showing the proportion of 'GREEN', 'AMBER' and 'RED' items in their outlet based on the Healthy Choices guidelines.

A simplified version of the Healthy Choices guidelines for drinks: ${ }^{9,10}$

\section{'GREEN' (best choices)}

- water (tap, still, sparkling, soda)

- flavoured water with natural essence (no added sugar or sweetener)

- reduced-fat plain milk

- reduced-fat flavoured milk, small (900kJ or less per bottle)

- tea/coffee with/without milk (no added sugar).

\section{'AMBER' (choose carefully)}

- full-fat plain milk

- flavoured milk (1600kJ or less per bottle)

- diet/artificially sweetened soft drinks, iced teas, sports drinks

- diet/artificially sweetened energy drinks (250ml or less)

- fruit juices (>99\% juice, no added sugar, $250 \mathrm{ml}$ or less)

- coconut water (no added sugar, 300kJ or less per bottle)

- kombucha (less than $1 \mathrm{~g}$ sugar per $100 \mathrm{ml}$, alcohol equal to or less than $0.5 \%$ )

- high protein drinks ( $300 \mathrm{ml}$ or less).

\section{'RED' (limit)}

- regular soft drinks, sports and energy drinks, cordials, flavoured iced teas, and mineral waters (with added sugar)

- fruit drinks and fruit juices (with added sugar or over $250 \mathrm{ml}$ )

- flavoured milk, large (more than 1600kJ per bottle)

- coconut water (with added sugar or over 300kJ per bottle)

- kombucha (1g or more sugar per $100 \mathrm{ml}$ or alcohol greater than $0.5 \%$ )

- high protein drinks (more than $300 \mathrm{ml}$ ).
To ensure classifications are up to date and accurate, you can also use FoodChecker. The Water in Sport project officers used FoodChecker to classify the drinks available in the sport and recreation or club facilities and find healthier drink options. They found that it was important to train and encourage outlet staff to learn how to use FoodChecker to reduce dependence on the project officer. Project officers also created personalised drink fridge planograms for the facilities based on the types of drinks they usually stocked and the shape of the fridge (see Resource 4d: Healthy fridge magnet and Resource 4e: Applying Healthy Choices to drinks in retail outlets).

\subsection{Understanding customer and staff opinions}

Surveying customers and staff formally with a questionnaire or informally by speaking with them can be a valuable way to understand the perspectives of those who will be impacted by the change (Resource 5: Customer and staff surveys). Findings can be used to demonstrate support for change to council and outlet leadership and can help inform the type of healthy changes the outlet will make (Resource 6: Survey results infographic template). Communicating with customers and staff during implementation and asking for feedback may also help them feel part of the change and help gain their support.

9 See Resource 3: Food and drink environment audit for a simplified version of the Healthy Choices guidelines for food

10 Department of Health and Human Services. Healthy Choices: food and drink classification guide. [cited Nov 2020]. Available from: https://www.health.vic.gov.au/ 


\subsection{Recommended changes}

Once you understand the context in which the food retail outlet operates and their current offerings, you are ready to decide what changes to make. Below are suggestions of how to use marketing techniques to ensure 'GREEN' products are highly visible, at a favourable price, and are promoted. These strategies are adapted from the Healthy Choices guidelines for sport and recreation centres $^{11}$.

\section{Product}

a. Product availability

i. 'GREEN' drinks should make up a larger portion of the fridge than 'RED' drinks.

b. Product size

i. If supplying 'RED' food and drinks, supply the smallest available size only.

\section{Pricing}

a. Increase the price of 'RED' food and drinks to subsidise a decrease in price of 'GREEN' food and drinks.

b. Provide discounted healthy meal deals or specials (e.g. sandwich plus water).

\section{Place}

a. Place 'GREEN' food and drinks in prominent locations; this includes the register, main entrance, and eye level on shelves.

b. Place 'RED' food and drinks out of sight of the customer such as behind the counter.

c. Cover 'RED' drinks using a poster on the outside of the fridge.

\section{Promotion}

a. Only promote 'GREEN' food and drinks and brands featuring 'GREEN' food and drinks (see Resource 4a: Drink fridge traffic light strip labels, Resource 4b: Traffic light food labels and Resource 4c: Water promotion poster).

\subsection{Setting goals with food retail outlets}

Establish SMART goals with the outlet manager or those that will be championing the change. This can provide targets to work towards and should be established early on. Be inclusive and responsive to different outlet personnel perspectives, concerns, and motivations and tailor your approach accordingly (Resource 7: SMART goals template).

SMART goals are:

- Specific: well defined, clear, and unambiguous.

- Measurable: a specific criterion that allows you to track your progress toward completing the goal.

- Achievable: attainable.

- Relevant: within reach, realistic, and relevant to the community food retail outlets.

- Timely: determine a clearly defined timeline, including a starting date and a target date to complete the change.

Example:

- Replace two product lines of 'RED' drinks with 'AMBER' drinks within three months (specify date).

- Cover all 'RED' drinks with a healthy drinks advertisement sticker within two months (specify date).

\subsection{Making your first change}

The easiest way to make changes is to simply get started now ${ }^{12}$. Start with small quick changes. These are often referred to as 'easy wins' as they are unlikely to have a negative impact, which could discourage the outlet from making further changes. It is a big win to make any sort of healthy change.

'Easy wins' are outlet-specific, and something that you should decide with the outlet. These are seen as easy or low risk and may include:

- Place 'GREEN' food and drinks at eye-level for customer.

- Place 'RED' food and drinks out of sight from customer (e.g. behind the counter).

- Cover all 'RED' drinks with a healthy drinks promotional poster.

11 Department of Health and Human Services. Healthy Choices: policy guidelines for sport and recreation centres 2016. [cited Nov 2020]. Available from: https://www.health.vic.gov.au/

12 Boelsen-Robinson T, Blake MR, Brown A, Huse 0, Palermo C, George N, et al. Mapping factors associated with a successful shift towards healthier food retail in community-based organisations: a systems approach. Food Policy. 2021 


\subsection{Training outlet staff}

Work with community food retail outlet staff to identify opportunities to provide training related to healthy food and drink provision. Basic training in the Healthy Choices guidelines will help sustain the change in the long-term. Tailored training that meets the goals and objectives of the specific outlet will enhance the session (Resource 8: retail outlet training template).

You may not get a chance to deliver any formal training, you could consider attending relevant staff meetings and providing the information in an informal way. The outlet manager or 'champion' could also deliver training or information on your behalf. Discuss with the outlet managers the best approach to deliver training.

Water in Sport learnings: importance of discussing changes with the facility

During the Water in Sport project, two sport and recreation facilities had fridges that were not visible to customers as the fridge was located under the counter. The 'nudges' required in the Water in Sport project assumed the fridge could be seen by the customer. Therefore a 'nudge' of limiting sugary drinks to less than $20 \%$ of fridge display or completely removing sugary drinks from display was not relevant. A focus was then placed on drinks advertising at these facilities. These facilities were encouraged to only display 'GREEN' or 'AMBER' drinks on the menu board or drink display. This demonstrates the importance of assessing the situation and working with the outlet champion collaboratively to make changes.

\subsection{Working with suppliers}

Find out which supplier the outlet receives their stock from and the terms of the contract, if they have one. Ask the following questions:

- Which suppliers do you purchase your drinks from?

- Do you have a contract with them? If so when does the contract expire?

- Are certain products required to be available or visible to customers?

- Are there restrictions on which products you can stock?

- Is certain fridge branding required?

Working with suppliers to make changes can be useful. You should encourage the outlet manager or champion to notify the supplier that the outlet will be making changes to the food and/or drinks offered. Open communication with the supplier including a brief overview of the Healthy Choices guidelines will help the supplier understand what food and/or drink to supply to the outlet (Resource 9: Email template to supplier).

If existing suppliers are unable to provide appropriate or affordable alternatives, where possible you could help the outlet source new or additional suppliers. HEAS can assist with overcoming any issues when dealing with suppliers.
Encourage suppliers to contact HEAS for support to classify their product portfolio according to Healthy Choices guidelines. This may increase the accuracy of the classifications they communicate to retailers, raise awareness about the healthiness of their current portfolio, and allow them to specifically market healthier alternatives to retailers.

When working with multiple outlets within a local government area, encourage the outlets to create a cooperative buyers' group to reduce the costs of healthier food and drink orders. A buyers' group enables outlets to demonstrate demand and purchase products in bulk, which can often be at a discounted rate.

\subsection{Providing ongoing council support}

Local government support and regular face-to-face, email or phone contact with managers and food outlet personnel will ensure outlets feel supported during each stage of the journey: planning, implementation, managing changes and maintenance.

You may consider establishing a local community-of-practice for outlet managers and staff involved in making the change. This will provide a supportive environment where outlet staff can share their experiences and issues and build a sense of community.

\section{Water in Sport community-of-practice}

HEAS facilitated two community-of-practice events per year during the Water in Sport project to encourage capacity building, and peer-to-peer support between the project officers. These structured workshops with HEAS, council project officers, Deakin University researchers, and VicHealth representatives provided formal training in 'nudge' implementation, use of FoodChecker, policy implementation and opportunities for project officer updates and group problem-solving. These sessions enabled sharing of knowledge and resources and provided inspiration and a feeling of solidarity for project officers. Project officers also supported each other outside these sessions through email and telephone calls, to share experiences and brainstorm ideas.

\section{"I think that the individuals were resources in themselves....We could have all the paper and online resources we want but individuals are sometimes the best wealth of information on how to navigate those or where we need to go as well."} Water in Sport - local government manager

\subsection{Recognition}

Recognise the achievements and progress of individual outlets towards healthier food and drink provision and acknowledge their efforts. Council can consider recognising community food retail outlets through:

- awards

- formal thanks from leadership:

- healthy signage within outlets

- external communication such as on council websites and social media. 


\subsection{Check in with the outlet}

Collecting evidence will help to determine whether the change has been successfully implemented, identify ways to improve the change, justify the use of resources, and allow the change to be adapted.

In the early stages, more frequent and intensive monitoring can ensure early identification of any concerns (e.g. every 2 weeks). However, as they begin to achieve their goal, less frequent (e.g. every 6 months) monitoring may be enough.

\subsection{Conduct photo audits}

A photo audit of the food and drink fridge display and the food outlet surroundings can help monitor the changes (Resource 2: Step-by-step photo audit). In the beginning, photos can help to establish a baseline and develop SMART goals. Once the goal has been achieved, photos can be taken regularly to monitor the maintenance of the change. Photos can also be used to enter products into FoodChecker to classify the proportion of food and drinks displayed as 'GREEN', 'AMBER' and 'RED'.

\subsection{Monitor outlet sales}

Sales data is one way to determine the success of the change, as you can determine the health of customer purchases and any changes to revenue post-implementation. However, sales data can be very complex to analyse and may not always be available. Sales can be affected by factors including weather, special events or closure periods and varying attendance rates. It is important to look at changes over the long-term (over 6 months) and compare sales to the same period in the previous year, as this will likely have similar sales patterns. When sales data is not available in a useable form, you could use anecdotal evidence to determine if the change is impacting sales (e.g. is the facility ordering fewer items overall from the supplier?)

\section{Step 4 Creating supportive policies}

A healthy food and drink policy sends a message to all stakeholders that enabling healthy eating is important to your local government. A policy can help ensure that any healthy changes made to create a supportive food and drink environment are sustained in the long-term. Consideration should be given to policy development early on. HEAS has developed a template to help organisations develop a healthy eating policy.

\subsection{What to consider when thinking about policies}

A one-size-fits-all policy may not suit your local government needs. It is important to consider the level of council influence on food and drink provision. A tiered policy approach can allow for different expectations depending on factors such as local government influence and capabilities.

A tiered approach to a healthy food and drink policy was developed by some Water in Sport local governments, to acknowledge that varying amounts of oversight on operations of user groups and facilities would impact their ability to enforce any changes. Additionally, outlets have different capabilities which need to be considered to ensure the policy is appropriate and able to be sustained.
A tiered approach may include the below categories, which should be tailored based on the type of community food retail outlets at the council:

- Tier 1 settings may have a high level of council oversight as well as a high level of complexity, including accountability, corporate responsibility, community safety, compliance, and/or quality standards implications, such as leisure centres.

- Tier 2 settings may have a lower level of council influence, and complexity/risk than Tier 1.

- Tier 3 settings may be council-owned or -managed premises which are leased to external parties or partner agencies (although operating at arm's length from Council) and typically used for their own purposes.

Additional things to consider including in a policy:

- Offering financial incentives for adoption and maintenance of healthy food and drink provision, such as fee exemptions for healthy food outlets; eligibility for funding and/or grants; and/ or a reduction in rent for user groups.

- Monitoring of healthy food and drink provision alongside routine site monitoring (e.g. incorporating a healthy food and drink check with regular food safety audits). 


\section{Acknowledgments}

This resource was created by VicHealth, in partnership with:

- Deakin University

- Healthy Eating Advisory Service at Nutrition Australia Vic Division

- Councils participating in the Water in Sport project.

\section{Authors}

Devorah Riesenberg, Tara Boelsen-Robinson, Adrian J Cameron, Anna

Peeters, Tara Heneghan, Kate Wilkinson and Miranda R Blake.

\section{More information}

This resource was originally created by VicHealth, Deakin University and the Healthy Eating Advisory Service. For more information, go to: www.vichealth.vic.gov.au/waterinsport

\section{Resources referenced in toolkit}

Resource 1: Readiness for change assessment

Resource 2: Step-by-step photo audit

Resource 3: Food and drink environment audit

Resource 4a: Drink fridge traffic light strip labels

Resource 4b: Traffic light food labels

Resource 4c: Water promotion poster

Resource 4d: Healthy fridge magnet

Resource 4e: Applying Healthy Choices to drinks in food retail outlets

Resource 5: Customer and staff surveys

Resource 6: Survey results infographic template

Resource 7: SMART goals template

Resource 8: Retail outlet training template

Resource 9: Email template to supplier

icHealth is committed to health equity, which means levelling the playing field between people who can easily access good health and people who face barriers, to achieve the highest level of health for everyone.

VicHealth acknowledges the support of the Victorian Government.

(c) VicHealth

February 2021

https://doi.org/10.37309/2021.HE1003

\section{VIGTORIA \\ State}

VicHealth acknowledges the Traditional Custodians of the land. We pay our respects to all Elders past, present and future. 